\title{
Improving reproductive health care services for women with a physical disability: Insights from a community survey of women with spinal cord injury in Switzerland
} \author{
study group ${ }^{\#}$ \\ ${ }^{1}$ Swiss Paraplegic Research (SPF), 6207 Nottwil, Switzerland \\ ${ }^{2}$ Department of Health Sciences and Medicine, University of Lucerne, 6000 Lucerne, Switzerland \\ ${ }^{3}$ Department of Obstetrics and Gynecology, Inselspital, 3010 Bern, Switzerland \\ ${ }^{4}$ Department of Obstetrics and Gynecology, Hospitals of Solothurn AG, 4500 Solothurn, Switzerland \\ ${ }^{\#}$ Membership of the SwiSCI Study Group is provided in the Acknowledgments.
}

Sue Bertschy ${ }^{*}$, Cristina Ehrmann ${ }^{1,2}$, Petra Stute ${ }^{3}$, Dimitrios Skempes ${ }^{1,2}$, Franziska Maurer-Marti ${ }^{4}$, Armin Gemperli ${ }^{1,2}$, on behave of SwiSCI

\begin{abstract}
Objective: To describe a cohort of women with a physical disability in various reproductive life stages to support the development of specific management targets, especially during the fertile stage.

Design: Community survey.

Population / Sample: We analysed data from 440 female participants with chronic spinal cord injury (SCI) aged over 16 years from the cross-sectional community survey of the Swiss Spinal Cord Injury Cohort Study (SwiSCI) in 2017.

Methods: The full cohort was analysed using descriptive analysis. For women in the fertile reproductive life stage, a regression technique was used to identify the predictors of becoming a mother after SCI.

Results: More than $50 \%$ of the sample were aged over 56, and approximately one fourth were in the fertile (16-45 years) age group. Motherhood after SCI was most prevalent in women with low and incomplete lesions and those who sustained an SCI at a young age. The chances of giving birth significantly decreased when sustaining an SCI after the age of 35 . The mean age at first delivery after SCI (age 31.2 \pm 5 years) was five years higher compared to women with an SCI who gave birth before sustaining SCI (age $26.2 \pm 5$ years).

Conclusions: The study provides evidence for the need for tailored and specific lifespan adjusted obstetric and gynaecological services for women with SCI and for women with a disability in general.
\end{abstract}

Funding: This study has been financed through the framework of the Swiss Spinal Cord Injury Cohort Study supported by the Swiss Paraplegic Foundation.

\section{Introduction}

Medical, demographic, and sociocultural shifts require adjustments of health systems to respond to the specific health needs of women with physical disabilities (WPD).

Whereas in the past women with WPD were seen by society as "sexually unattractive" and stigmatised, recent advances in medicine and non-discrimination policies have empowered WPD to participate normally in daily life. Currently, WPD do not receive the same quality of ObGyn care as non-disabled women [1]. Many health systems, including those in high-income countries, are struggling to cope with the health needs of the steadily growing number of WPD [2]. Services on reproductive health are not routinely provided to WPD as part of standard obstetric and gynaecological (ObGyn) health care. Thus, WPD are less likely to receive preventive measures (e.g. pelvic exams, PAP smears, mammograms), and counselling on family planning (e.g., contraception, infertility treatment), pregnancy and menopause $[3,4]$.
Disabilities vary significantly and while some health conditions associated with disabilities result in poor health and extensive health care needs, others do not. Thus, services need to be specifically tailored to individuals' health needs. For example, women with neurological disorders, such as SCI, commonly suffer from motor and sensory impairments [5]. Due to the effects of such impairment (e.g. temperature dysregulation, neurogenic bowel and bladder, altered sexual response), women with SCI may experience greater severity

${ }^{*}$ Correspondence to: Sue Bertschy, Ph. D., SPF - Swiss Paraplegic Research, Guido A. Zäch-Strasse 4 CH-6207 Nottwil, Switzerland, E-mail: sue.bertschy@ paraplegie.ch

Key words: spinal cord injury, gynecological services, fertility, motherhood, management of women with a disability, life stages

Received: August 12, 2020; Accepted: October 01, 2020; Published: October 07,2020 
Bertschy S (2020) Improving reproductive health care services for women with a physical disability: Insights from a community survey of women with spinal cord injury in Switzerland

of symptoms (e.g. vaginal dryness or increased risk for osteoporosis) or need tailored medications [6]. Thus, WPD require proper life stage adjusted services and an interconnected health system for effective disability management. Improving the process of care for women with an SCI during their reproductive lifespan should lead to improvements in many other conditions and lifespan needs as well. However, if left unmanaged, adverse health outcomes could exacerbate existing comorbidities.

Currently, information from national surveys is not properly disaggregated by disability status [7]. Thus, nationally representative information related to reproductive health care for WPD (e.g. maternity care) is lacking. The Swiss Spinal Cord Injury Cohort Study (SwiSCI) [8] offers such data and the unique opportunity to study the reproductive health and care of WPD. This is important since, individuals with SCI constitute a highly representative group of people living with physical disabilities. The aim of this study was to describe a cohort of WPD (specifically, with SCI) in various reproductive life stages to support the development of specific management targets, especially during the fertile life stage.

\section{Methods}

\section{Study design and participants}

This was a cross-sectional study of women with SCI who participated in the community survey of the SwiSCI conducted in 2017 [8]. SwiSCI is part of the International Spinal Cord Injury (InSCI) survey, an initiative that coordinates community surveys on SCI in more than 20 countries [9]. Female Swiss residents with traumatic or non-traumatic SCI were eligible and included in the study. Exclusion criteria were age below 16 years, a new SCI in the context of end of life, an SCI due to congenital conditions (e.g. spina bifida), neurodegenerative disorders (e.g. multiple sclerosis) or Guillain-Barre syndrome.

\section{Measures}

Demographic and injury characteristics: Self-reported information on sex, age, education (years of formal education), etiology (traumatic or non-traumatic), lesion level (paraplegia or tetraplegia), lesion completeness (complete or incomplete), birth country, date of SCI, language and SCI cause were collected.

Motherhood: Woman were asked to provide the date of delivery of their biological children.

\section{Statistical analysis}

Total cohort of women with SCI in the 2017 community SwiSCI survey: The reproductive life stages of women were categorised according the STRAW staging system [10] as follows: fertile age: 1645 years; perimenopause/early postmenopause: 46-55 years; late postmenopause I: 56-70 years; and late postmenopause II: 70+ years). Additionally, the reproductive behaviour of women (being a mother before SCI, being a mother after SCI, being a mother before and after SCI, being childless) was described. Moreover, a pyramid chart was used to illustrate the percentage of women having children after an SCI versus the percentage of women not having children after an SCI, stratified by age at SCI.

Cohort of women in the fertile reproductive life stage at the SCI event: Descriptive statistics were provided for demographics and injury characteristics and grouped by reproductive behaviour. Univariate and multivariable logistic regression analyses were performed to calculate unadjusted and adjusted odds ratios (OR) of the likelihood of becoming a mother after the SCI event with selected predictive variables: age at injury, level of education, injury level and completeness, and birth country. To account for item nonresponse (i.e., missing items of predictive variables for a subset of participants), a random forest imputation technique was used with the assumption that data were missing at random [11]. For women who became mothers after the SCI, the timespan between the age at injury and the first delivery was displayed by cross plotting the age at injury and the age at delivery of the first child. Moreover, the ages at the first and second deliveries after the SCI were cross-plotted. The data analyses were conducted using R version 3.5.0.

\section{Results}

\section{Total cohort of women with SCI from the 2017 community SwiSCI survey}

A total of 440 women with SCIs participated in the 2017 SwiSCI cohort study. Reproductive behaviour and reproductive life stage information is presented in Table 1. At the time of the survey, almost one in four women $(24 \%)$ was in the fertile stage. One in two women was childless $(n=205)$, while 64 women gave birth to their first child after sustaining an SCI. Few women $(n=8)$ delivered a child before and after the SCI event.

Figure 1 presents the percentage of women who delivered a child after the SCI event grouped by age at the time of injury. Only women who provided information about their age at injury were considered $(n=402)$. Overall, 72 women had a delivery after the SCI event. Of those, nine (21\%) women were aged 31-35 years, and two (5\%) women were aged $36+$ years when sustaining an SCI.

\section{Cohort of women in the fertile reproductive life stage at the SCI event}

Overall, 264 women were in the fertile life stage when they were affected by an SCI. Of those, 124 women (47\%) had children at a mean age of first delivery of 29 years $(\mathrm{SD}=6)$. In detail, mean age at first delivery was 26 years $(S D=5)$ in women who had children before the SCI event, 26 years $(S D=7)$ in women who had children before and after the $\mathrm{SCI}$ event, and 31 years $(\mathrm{SD}=5)$ in women who delivered their first child after the SCI event. Women who delivered their first child after the SCI event had more years of education compared to women with deliveries before the SCI those with deliveries before and after the SCI event. Of the entire cohort $(n=264)$, almost three-quarters $(74 \%)$ were classified as paraplegia, and $60 \%$ had incomplete lesions. Most women were born in Switzerland, long educated, and had a traumatic SCI (Table 2).

Table 3 presents the results of the univariate (unadjusted model) and multivariable (adjusted model) logistic analyses. The likelihood of being a mother was significantly associated with SCI aetiology and age at injury. More specifically, the chance of motherhood was significantly decreased by $61 \%$ in women with non-traumatic injury (OR 0.39; $95 \%$ CI 0.16-0.84). Similarly, higher age at injury was associated with a significantly lower chance of motherhood (OR 0.94; 95\% CI 0.91-0.97).

Figure 2 (A) shows the number of women by the age at SCI and the age at first delivery after the SCI event. Overall, 72 women delivered children after the SCI event. The time between the SCI event and first delivery after the SCI event ranged from 0 to 5 years in 34 women (47\%), from 6 to 10 years in $12(17 \%)$, from 11 to 15 years in $16(22 \%)$, from 16 to 20 years in seven $(10 \%)$, and $20+$ years in three (4\%). Fortytwo women with SCI before the age of 30 delivered their first child 
Bertschy S (2020) Improving reproductive health care services for women with a physical disability: Insights from a community survey of women with spinal cord injury in Switzerland

Table 1. Reproductive life stages and reproductive behaviour of women participating in the SwiSCI community survey 2017

\begin{tabular}{|c|c|c|c|c|c|}
\hline Age/reproductive stage at survey participation (N (\%)) & $\begin{array}{c}\text { Total } \\
(\mathrm{N}=\mathbf{4 4 0})\end{array}$ & $\begin{array}{c}\text { Children before SCI } \\
(\mathrm{N}=163)\end{array}$ & $\begin{array}{l}\text { Children after SCI } \\
\qquad(N=64)\end{array}$ & $\begin{array}{l}\text { Children before } \\
\text { and after SCI } \\
(\mathrm{N}=8)\end{array}$ & $\begin{array}{c}\text { No children } \\
(\mathrm{N}=\mathbf{2 0 5})\end{array}$ \\
\hline Fertile Age, $16-45$ years & $103(24)$ & $7(7)$ & $22(21)$ & $1(1)$ & $73(71)$ \\
\hline Peri-/Early postmenopause, $46-55$ years & $110(25)$ & $25(23)$ & $25(23)$ & $3(3)$ & $57(52)$ \\
\hline Late postmenopause I, 56-70 years & $142(32)$ & $78(55)$ & $16(11)$ & $3(2)$ & $45(32)$ \\
\hline Late postmenopause II, $70+$ years & $85(19)$ & $53(62)$ & $1(1)$ & $1(1)$ & $30(35)$ \\
\hline Age at SCI (Mean (SD)) & $38(18)$ & $53(14)$ & $22(6)$ & $32(6)$ & $31(16)$ \\
\hline
\end{tabular}

Table 2. Sociodemographic characteristics of fertile women (age 16-45 years) at the time of the SCI event

\begin{tabular}{|c|c|c|c|c|c|}
\hline & \multirow[b]{2}{*}{$\begin{array}{c}\text { Total } \\
(\mathbf{N}=\mathbf{2 6 4})\end{array}$} & \multicolumn{3}{|c|}{ Mothers (N=124) } & \multirow[b]{2}{*}{$\begin{array}{l}\text { No children } \\
(\mathrm{N}=140)\end{array}$} \\
\hline & & $\begin{array}{l}\text { Children before SCI } \\
\qquad(\mathrm{N}=52)\end{array}$ & $\begin{array}{l}\text { Children after SCI } \\
\qquad(\mathrm{N}=64)\end{array}$ & $\begin{array}{c}\text { Children before and } \\
\text { after SCI } \\
(\mathbf{N}=8)\end{array}$ & \\
\hline \multicolumn{6}{|l|}{$\begin{array}{l}\text { Language of the questionnaire } \\
(\mathrm{N}(\%))(\text { Missing, } \mathrm{N}=3)\end{array}$} \\
\hline German & $189(72)$ & $38(20)$ & $52(27)$ & $5(3)$ & $94(50)$ \\
\hline French & $66(25)$ & $13(20)$ & $10(15)$ & $3(5)$ & $40(60)$ \\
\hline Italian & $9(3)$ & $1(11)$ & $2(22)$ & - & $6(67)$ \\
\hline \multicolumn{6}{|l|}{ Country born (N (\%)) (Missing, $\mathrm{N}=2)$} \\
\hline Foreigner & $44(17)$ & $11(25)$ & $10(23)$ & $4(9)$ & $19(43)$ \\
\hline Swiss & $218(83)$ & $40(18)$ & $53(24)$ & $4(2)$ & $121(56)$ \\
\hline $\begin{array}{l}\text { Woman's education (years) (Median, (Q1-Q3)) (Missing, N } \\
\qquad=12)\end{array}$ & $13(12-17)$ & $13(10-14)$ & $13(12-16)$ & $15(13-17)$ & $14(12-17)$ \\
\hline \multicolumn{6}{|l|}{$\begin{array}{l}\text { Woman's education }(\mathrm{N}(\%)) \\
\text { (Missing, } \mathrm{N}=12)\end{array}$} \\
\hline $0-8$ years & $8(3)$ & $5(62)$ & - & - & $3(38)$ \\
\hline $9-12$ years & $73(29)$ & $18(25)$ & $21(29)$ & $2(3)$ & $32(43)$ \\
\hline $13-15$ years & $91(36)$ & $15(17)$ & $24(27)$ & $3(3)$ & $49(53)$ \\
\hline more 15 years & $80(32)$ & $9(11)$ & $16(20)$ & $3(4)$ & $52(65)$ \\
\hline \multicolumn{6}{|l|}{ Aetiology $(\mathrm{N}(\%))($ Missing, $\mathrm{N}=3$ ) } \\
\hline Traumatic & $207(79)$ & $37(18)$ & $55(27)$ & $7(3)$ & $108(52)$ \\
\hline \multicolumn{6}{|l|}{ Traumatic SCI cause: } \\
\hline Sport accident & $39(15)$ & $3(8)$ & $11(28)$ & $2(5)$ & $23(59)$ \\
\hline Accident at leisure activities & $38(14)$ & $6(16)$ & $13(34)$ & - & $19(50)$ \\
\hline Work accident & $10(4)$ & $4(40)$ & $2(20)$ & - & $4(40)$ \\
\hline Traffic accident & $87(33)$ & $14(16)$ & $23(26)$ & $4(5)$ & $46(53)$ \\
\hline Assault & $10(4)$ & - & $3(30)$ & - & $7(70)$ \\
\hline Fall from less than $1 \mathrm{~m}$ & $6(2)$ & $2(33)$ & $2(33)$ & - & $2(33)$ \\
\hline Fall from more than $1 \mathrm{~m}$ & $56(21)$ & $13(23)$ & $14(25)$ & $3(5)$ & $26(47)$ \\
\hline Surgical / medical complication & $6(2)$ & $2(33)$ & $1(17)$ & - & $3(50)$ \\
\hline Other cause & $5(2)$ & - & - & - & $5(100)$ \\
\hline Nontraumatic & $54(21)$ & $15(28)$ & $8(15)$ & - & $31(57)$ \\
\hline \multicolumn{6}{|l|}{ Nontraumatic SCI cause } \\
\hline Vertebral column degenerative disorder & $17(6)$ & $5(29)$ & $2(12)$ & - & $10(59)$ \\
\hline Tumour - benign & $19(7)$ & $7(37)$ & $4(21)$ & - & $8(42)$ \\
\hline Tumour - malign (cancer) & $3(1)$ & $1(33)$ & - & - & $2(67)$ \\
\hline Vascular disorder & $11(4)$ & $4(36)$ & $1(9)$ & - & $6(55)$ \\
\hline Infection & $8(3)$ & $1(12)$ & $1(12)$ & - & $6(75)$ \\
\hline Other disease & $5(2)$ & $2(40)$ & - & - & $3(60)$ \\
\hline \multicolumn{6}{|l|}{$\begin{array}{l}\text { SCI severity (N (\%)) } \\
\text { (Missing, } \mathrm{N}=18)\end{array}$} \\
\hline Paraplegia complete & $77(31.3)$ & $11(14)$ & $22(29)$ & $1(1)$ & $43(56)$ \\
\hline Paraplegia incomplete & $106(43.1)$ & $6(29)$ & $3(14)$ & - & $12(57)$ \\
\hline Tetraplegia complete & $21(8.5)$ & $27(25)$ & $26(25)$ & $5(5)$ & $48(45)$ \\
\hline Tetraplegia incomplete & $42(17.1)$ & $3(7)$ & $9(21)$ & $2(5)$ & $28(67)$ \\
\hline
\end{tabular}

Abbreviation: Q1=first quartile: $25 \%$ of data are smaller or equal to this value; $\mathrm{Q} 3=$ third quartile: $75 \%$ of data are smaller or equal to this value. 
Bertschy S (2020) Improving reproductive health care services for women with a physical disability: Insights from a community survey of women with spinal cord injury in Switzerland

Table 3. Multivariable regression analyses for the binary outcome "being a mother after the SCI event" (yes vs. no) (imputed dataset; $n=264$; unadjusted model and model adjusted for all variables)

\begin{tabular}{|c|c|c|c|c|c|c|c|c|}
\hline & \multicolumn{8}{|c|}{ Being a mother after the SCI event } \\
\hline & \multicolumn{4}{|c|}{ Unadjusted model } & \multicolumn{4}{|c|}{ Adjusted model } \\
\hline & \multirow[b]{2}{*}{ OR } & \multicolumn{2}{|c|}{$95 \% \mathrm{CI}$} & \multirow[b]{2}{*}{$\mathrm{p}$} & \multirow[b]{2}{*}{ OR } & \multicolumn{2}{|c|}{$95 \% \mathrm{CI}$} & \multirow[b]{2}{*}{$\mathrm{p}$} \\
\hline & & Lower & Upper & & & Lower & Upper & \\
\hline Age at injury & 0.94 & 0.91 & 0.97 & $<0.001$ & 0.94 & 0.91 & 0.97 & $<0.001$ \\
\hline Country born & & & & 0.464 & & & & 0.266 \\
\hline Foreigner & 1 & & & & 1 & & & \\
\hline Swiss & 0.76 & 0.38 & 1.58 & & 0.65 & 0.31 & 1.39 & \\
\hline Woman's education (years) & 0.99 & 0.92 & 1.07 & 0.910 & 0.98 & 0.90 & 1.06 & 0.745 \\
\hline Aetiology & & & & 0.015 & & & & 0.044 \\
\hline Traumatic & 1 & & & & 1 & & & \\
\hline Nontraumatic & 0.39 & 0.16 & 0.84 & & 0.39 & 0.15 & 0.88 & \\
\hline SCI severity & & & & 0.312 & & & & 0.177 \\
\hline Paraplegia complete & 1 & & & & 1 & & & \\
\hline Paraplegia incomplete & 0.32 & 0.07 & 1.04 & & 0.32 & 0.07 & 1.08 & \\
\hline Tetraplegia complete & 0.86 & 0.46 & 1.62 & & 1.26 & 0.64 & 2.48 & \\
\hline Tetraplegia incomplete & 0.87 & 0.38 & 1.95 & & 1.03 & 0.42 & 2.46 & \\
\hline
\end{tabular}

Abbreviations: $\mathrm{OR}=$ odds ratio, $\mathrm{CI}=$ confidence interval; $\mathrm{p}$-values $<0.05$ are bolded.

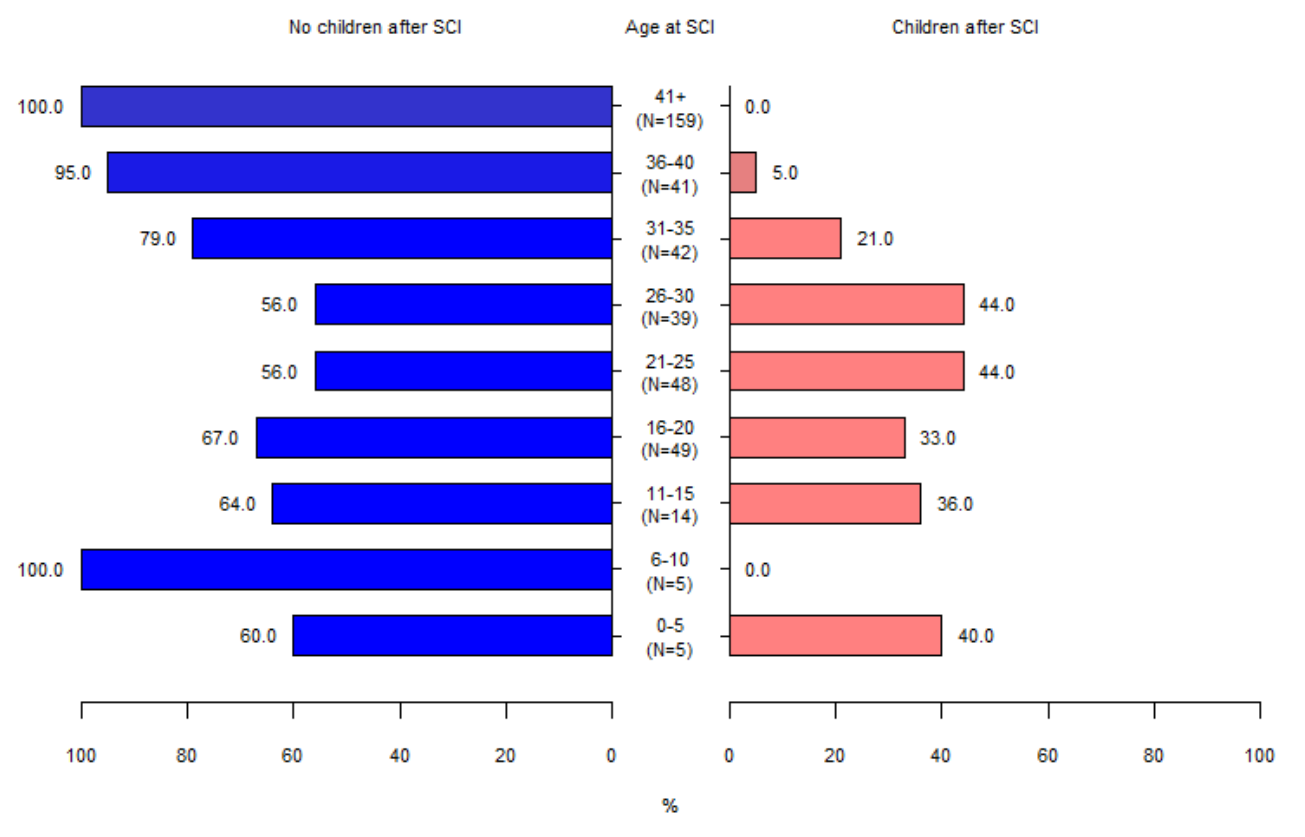

Figure 1. Pyramid displaying the percentage of women becoming mothers after the SCI grouped by age at SCI (N=402)

after age 30 . Of those, 15 women had a second child after the age of 36 (Figure $2(\mathrm{~B})$ ).

\section{Discussion}

\section{Main findings}

To the best of our knowledge, this is the first study to provide data on reproductive behaviour in women with SCI. The chance of becoming a mother after SCI $(n=440,16 \%)$ was comparable to that found in previous studies from other high-income countries, which make considerable investments in rehabilitation and health care, with reported delivery rates between 14 and 18\% [12]. Time to first delivery after the SCI was up to 5 years in almost $50 \%$ of the SCI women. Regarding predictors for motherhood, young age at injury was significant, similar to a previous US study [13]. In our study, an additional significant predictor for motherhood after SCI was sustaining a traumatic injury (e.g. traffic accidents and accidents during leisure activities). When comparing the severity of SCI between the various studies some discrepancies appear. For example, one retrospective cohort study involving 25 women with SCI reported mainly those with complete lesions [14] became mother after SCI, while in our study mainly women with incomplete or low lesions became mothers.

Age-related fertility decline is a general but often neglected phenomenon in women, with fertility declining with advancing age, especially after the mid-30s [15]. To date, there is no evidence showing 

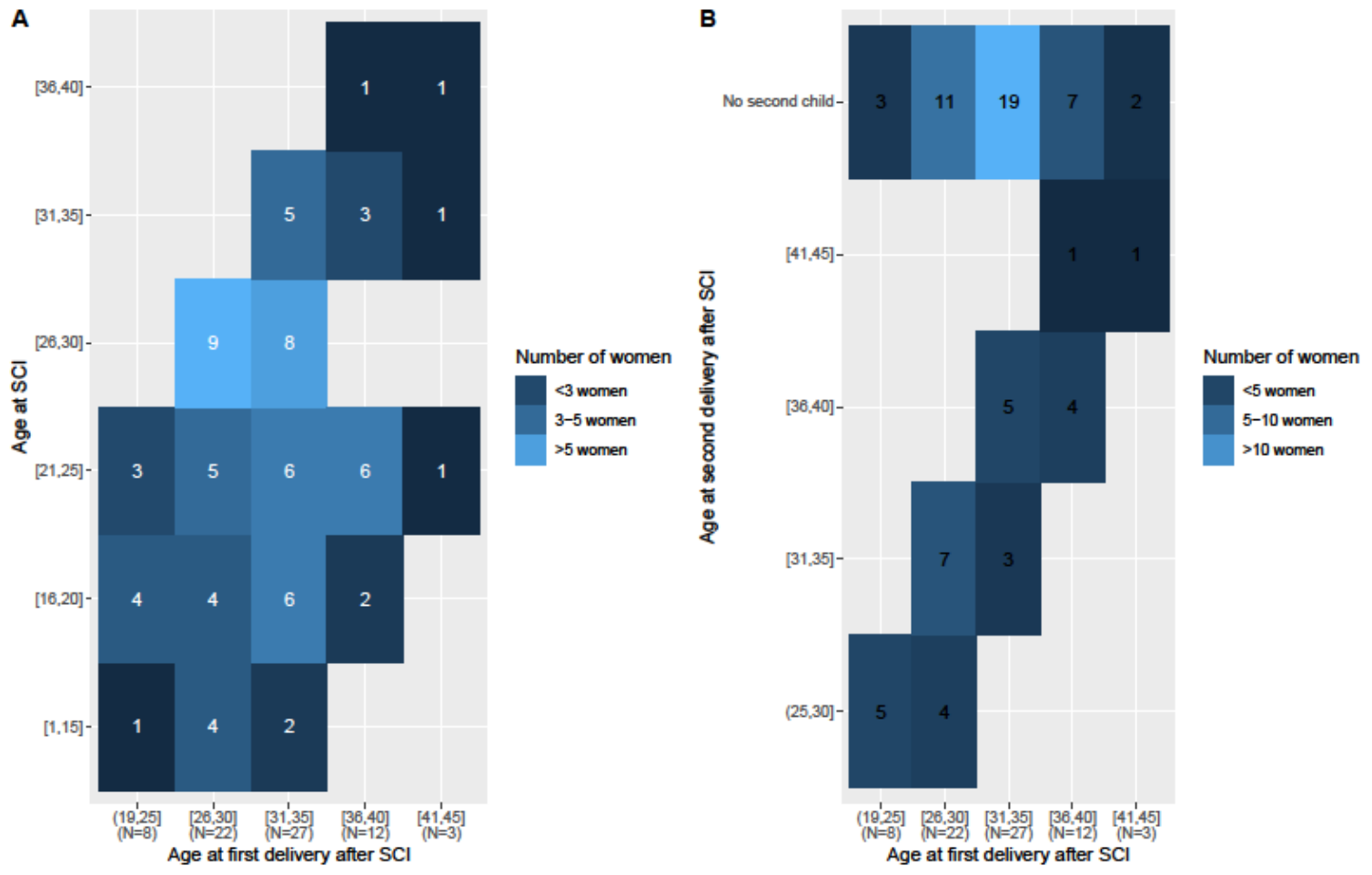

Figure 2. Graph shows the number of women by (A): age at SCI and age at first delivery after SCI and (B) age at first and second delivery after SCI

that an SCI induces hormonal changes impacting fertility [16]. We observed a similar pattern in our cohort, where women with an SCI gave birth until the age of 44 . However, we observed an important decrease in a woman's chance of motherhood when sustaining the SCI after the age of 35 . Moreover, in our cohort, more than $50 \%$ of the women with SCI were above age 56 when participating in the survey, and so themes such as menopause and related co-morbidities were predominant.

\section{Strengths and limitations}

This study is inherently subject to several limitations. First, despite the rather extensive recruitment efforts, the obtained sample size of women with SCI who became mothers after the SCI event $(n=72)$ was relatively small. One reason for this might be that there is no national registry for people with SCI. The SwiSCI cohort study, which collected data from four Swiss rehabilitation centres, may not represent the whole national SCI cohort and might thus underrepresent women with SCI, the elderly and those with very low lesions (L1-S5) [17]. In addition, this survey includes no further information about conceiving and pregnancy outcomes. SwiSCI does not gather data on miscarriages, pregnancy outcomes (e.g. premature or term births, caesarean deliveries). Further, SwiSCI does not identify first-time pregnancies, whether women have difficulty conceiving, or whether they used assisted reproductive services to become pregnant. Finally, although some relevant variables (e.g. educational status, SCI aetiology) were considered for analysis, information on other potential predictors of the likelihood of motherhood (e.g. marital status, work status, finances, satisfaction with health and quality of life) were only available for the 3-month-period prior to the survey but not for the time of the delivery or SCI event. Despite these shortcomings, this study offers insight not only into fertile women but also in the entire cohort of women with SCI, allowing the formulation of recommendations for policy and service provision.

\section{Interpretation}

Our findings show that women with SCI are represented in all life stages, underlining the need for tailored services related to their obstetric and gynaecological needs [3]. In our sample, one-fourth of the women were in the fertile life stage, where counselling on family planning, contraception, infertility/sterility treatment and pregnancy/ lactation is predominant. For example, contraception counselling usually considers the female's age, personal and family history, family planning and the personal preferences. Counselling women with SCI who are at additional increased risk for venous thromboembolism due to their medical history, requires additional expertise. This because they are not optimal candidates for combined oral contraception; rather, they should be prescribed a non-hormonal or progestin-only contraception [18].

Family planning decisions and health care service utilisation depend on several individual factors as well as societal- and institutional-level factors. In our study, only women with a lower incomplete lesion became mothers. Thus, a woman's personal characteristics (e.g. age, education, health status, social identity) may interfere with health care system structures and processes, creating a barrier to accessing family planning services [19]. This potential barrier could be further aggravated by environmental barriers, such as the lack of physical accessibility [20]. Furthermore, institutional-level barriers, such as the lack of national guidelines on reproductive care in WPD and issues with insurance coverage and affordability, may present obstacles to the development of high-quality, responsive gynaecological services.

However, most of the study participants were in the peri- and postmenopausale life stage. In this stage, womens' service needs change, with focus on acute menopausal symptom relief and longterm prevention of chronic non-communicable diseases. At this 
Bertschy S (2020) Improving reproductive health care services for women with a physical disability: Insights from a community survey of women with spinal cord injury in Switzerland

age, menopause has usually occurred, and this may be associated with various oestrogen deficiency-related acute symptoms (e.g. hot flushes, insomnia, depression, urogenital atrophy) and chronic health conditions (e.g. osteoporosis, cardiovascular disease). For example, due to estrogen deficiency the risk of recurrent urinary tract infections is increased in all menopausal women. In women with SCI, this risk is already increased by self-catheterising. To avoid further risks, it is preferable to initiate a local estrogen therapy [6].

In Switzerland, some first steps have been taken to improve ObGyn health care services for women with SCI. For example, an interdisciplinary international guideline on maternity care has recently been published [21]. However, more needs to be done to address the multifaceted barriers affecting WPD [20]. In this regard, specific modules should be added to the standard gynaecological residency curriculum along with continuous professional development courses for practicing gynecologists. The goal is to establish the necessary knowledge base for counselling women with disability-specific complications [22]. Development of on-line training tools such as videos explaining aspects of the gynaecological examination and care, could aid providers in aligning their practice with best evidence and help institute a culture of patient centeredness, respect for autonomy and holistic care [23].

Health care providers and clinics could also take measures to make their practice more accessible and inclusive by ensuring that equipment, facilities and information are accessible to WPD. In Switzerland, the umbrella organisation for disabled persons has developed a checklist to assist health care providers in assessing physical accessibility of their facilities and their conformance with national standards. Finally, stereotypes and discriminatory attitudes against women with disabilities must be eliminated through appropriate health professional education and awareness. An overall national framework for improving the reproductive health of women with disabilities and SCI would be in alignment with WHO recommendations [24] and published evidence [25] is needed to ensure that women with disabilities enjoy their fundamental right to access reproductive and sexual healthcare.

\section{Conclusion}

After acquiring an SCI, the majority of women who became mothers are those with low and incomplete lesions. Moreover, there seem to be no fertility issues related to impairment or age other than the biological age for motherhood. Women of all reproductive stages were represented in this study, meaning that all women need to be counselled with respect to their reproductive life stage (family planning, contraception, infertility/sterility treatment, pregnancy/lactation, peri- and postmenopause). In addition, a holistic, inter-professional approach is needed to educate reproductive health professionals to improve the quality of ObGyn care for women with SCI and disabilities in general. Strengthening ObGyn services would likely result in cost savings for the health system, improve individual health outcomes and promote social inclusion and participation.

\section{Author contributions}

SB led the study design and contributed to the data analysis, manuscript writing and revision. CE provided technical oversight of the data analysis and validation and contributed to the manuscript writing. PS contributed to the data interpretation, and manuscript writing. DS and FM contributed to the data interpretation and manuscript writing/revision. AG contributed to the study design and manuscript revision.

\section{Acknowledgments}

We are grateful to all the participants of the SwiSCI survey for their time and effort spent in responding to the questions. The members of the SwiSCI Steering Committee are: Xavier Jordan, Fabienne Reynard (Clinique Romande de Réadaptation, Sion); Michael Baumberger, Hans Peter Gmünder (Swiss Paraplegic Center, Nottwil); Armin Curt, Martin Schubert (University Clinic Balgrist, Zürich); Margret HundGeorgiadis, Kerstin Hug (REHAB Basel, Basel); Urs Styger (Swiss Paraplegic Association, Nottwil); Daniel Joggi (Swiss Paraplegic Foundation, Nottwil); NN (Representative of persons with SCI); Nadja Münzel (Parahelp, Nottwil); Mirjam Brach, Gerold Stucki (Swiss Paraplegic Research, Nottwil); Armin Gemperli (SwiSCI Coordination Group at Swiss Paraplegic Research, Nottwil)..

\section{Funding}

This study has been financed in the context of the Swiss Spinal Cord Injury Cohort Study (SwiSCI) sponsored by the Swiss Paraplegic Foundation.

\section{Conflicts of interest}

None declared.

\section{Details of ethics approval}

The survey was approved by the local cantonal ethical committees of Lucerne, Basel, Valais, and Zurich (reference numbers: 1008 [Luzern]; 37/11 [Basel]; CCVEM 015/11 [Valais]; 2012-0049 [Zürich]). Informed consent was obtained from all participants prior to their participation in the survey.

\section{References}

1. Nosek MA, Howland C, Rintala DH, Young ME, Chanpong GF (2001) National study of women with physical disabilities: Final report. Sexuality and Disability 19: 5-10.

2. Organization WH. Reproductive health Geneva2016 [Available from: http://www.who. int/topics/reproductive_health/en/.

3. Parish SL, Huh J (2006) Health care for women with disabilities: Population-based evidence of disparities. Health Soc Work 31: 7-15. [Crossref]

4. Schopp LH, Sanford TC, Hagglund KJ, Gay JW, Coatney MA (2002) Removing service barriers for women with physical disabilities: promoting accessibility in the gynecologic care setting. J Midwifery Womens Health 47: 74-79. [Crossref]

5. Park SE, Elliott S, Noonan VK, Thorogood NP, Fallah N, et al. (2017) Impact of bladder, bowel and sexual dysfunction on health status of people with thoracolumbar spinal cord injuries living in the community. J Spinal Cord Med 40: 548-559. [Crossref]

6. Kalpakjian CZ, Quint EH, Bushnik T, Rodriguez GM, Terrill MS (2010) Menopause characteristics and subjective symptoms in women with and without spinal cord injury. Arch Phys Med Rehabil 91: 562-569. [Crossref]

7. Swiss National Health Survey, (2017).

8. Post MWM, Brinkhof MWG, von Elm E, Boldt C, Brach M, et al. (2011) Design of the Swiss Spinal Cord Injury Cohort Study (SwiSCI). Am J Phys Med Rehabil 90: 5-16.

9. Gross-Hemmi MH, Post MW, Ehrmann C, Fekete C, Hasnan N, et al. (2017) Study protocol of the International Spinal Cord Injury (InSCI) community survey. Am J Phys Med Rehabil 96: S23-S34. [Crossref]

10. Harlow SD, Gass M, Hall JE, Lobo R, Maki P, et al. (2012) Executive summary of the Stages of Reproductive Aging Workshop + 10: addressing the unfinished agenda of staging reproductive aging. Fertil Steril 97: 843-851. [Crossref]

11. Tang F, Ishwaran H (2017) Random forest missing data algorithms. Stat Anal Data Min 10: 363-377.

12. Jackson AB, Wadley V (1999) A multicenter study of women's self-reported reproductive health after spinal cord injury. Arch Phys Med Rehabil 80: 1420-1428. [Crossref] 
Bertschy S (2020) Improving reproductive health care services for women with a physical disability: Insights from a community survey of women with spinal cord injury in Switzerland

13. Iezzoni LI, Chen Y, McLain ABJ (2015) Current pregnancy among women with spinal cord injury: findings from the US national spinal cord injury database. Spinal Cord 3: 821-826. [Crossref]

14. Le Liepvre H, Dinh A, Idiard-Chamois B, Chartier-Kastler E, Phe V, et al. (2016) Pregnancy in spinal cord-injured women, a cohort study of 37 pregnancies in 25 women. Spinal Cord 55: 167-171. [Crossref]

15. Garcia D, Brazal S, Rodriguez A, Prat A, Vassena R (2018) Knowledge of age-related fertility decline in women: A systematic review. Eur J Obstet Gynecol Reprod Biol 230: 109-118. [Crossref]

16. Lombardi G, Mondaini N, Macchiarella A, Popollo GD (2007) Female sexual dysfunction and hormonal status in spinal cord injured (SCI) patients. J Androl 28: 722-726. [Crossref]

17. Chamberlain JD, Ronca E, Brinkhof MW (2017) Estimating the incidence of traumatic spinal cord injuries in Switzerland: Using administrative data to identify potential coverage error in a cohort study. Swiss Med Wkly 147: w14430. [Crossref]

18. American College of Obstetricians and Gynecologists (2002) Obstetric Management of Patients with Spinal Cord Injuries. In: ACOG Committee CoOP, editor.: Int J Gynecol Obstet 189-191.

19. Schopp LH, Kirkpatrick HA, Sanford TC, Hagglund KJ, Wongvatunyu S (2002) Impact of comprehensive gynecologic services on health maintenance behaviours among women with spinal cord injury. Disabil Rehabil 24: 899-903.
20. Bertschy S, Geyh S, Pannek J, Meyer T (2015) Perceived needs and experiences with healthcare services of women with spinal cord injury during pregnancy and childbirth - a qualitative content analysis of focus groups and individual interviews. BMC Health Serv Res 15: 234. [Crossref]

21. Bertschy S, Schmidt M, Fiebag K, Lange U, Kues S, et al. (2020) Guideline for the management of pre-, intra-, and postpartum care of women with a spinal cord injury. Spinal Cord 58: 449-458.

22. Iezzoni LI, Wint AJ, Smeltzer SC, Ecker JL (2015) Effects of disability on pregnancy experiences among women with impaired mobility. Acta Obstet Gynecol Scand 94: 133-140. [Crossref]

23. (UAB-SCIMS) SCIMS. Reproductive Health for Women with Spinal Cord Injury Video Series Birmingham: The University of Alabama at Birmingham; 2020 [Available from: https://www.uab.edu/medicine/sci/uab-scims-information/reproductive-healthfor-women-with-spinal-cord-injury-video-series.

24. World Health Organization. Promoting sexual and reproductive health for person with disabilities: WHO/UNFPA Guidance Note. In: Research DoRHa, editor. GenevaSwitzerland: WHO/UNFPA; 2009. p. 40.

25. Mitra M, Long-Bellil LM, Smeltzer SC, Iezzoni LI (2015) A perinatal health framework for women with physical disabilities. Disabil Health J 8: 499-506. [Crossref]

Copyright: $@ 2020$ Bertschy S. This is an open-access article distributed under the terms of the Creative Commons Attribution License, which permits unrestricted use, distribution, and reproduction in any medium, provided the original author and source are credited. 